\title{
A Novel PbS Nanparticle Based Electrochemical Codeine Sensor
}

\author{
Hong PENG ${ }^{1}$, SuFang $\mathrm{WU}^{2}$, Guobing $\mathrm{WEI}^{1}$, Fusheng $\mathrm{LIAO}^{1}$ and Hao FAN ${ }^{1}$ * \\ ${ }^{1}$ Department of Pharmacy, JiangXi University of Traditional Chinese Medicine, JiangXi 330004, China \\ ${ }^{2}$ JiangXi Nursing Vocational and Technical College, JiangXi 330004, China \\ 1516531260@qq.com²49361941@qq.com,*fanhao11@aliyun.com,,359214445@qq.com, \\ 1470580951@qq.com
}

\begin{abstract}
In the present study, we describe an electrochemical sensor for codeine detection by using the DNA aptamers against codeine. In the sensing protocol, a dually-labeled DNA Aptamer probe was designed to be labeled at one end with HS, and at its another end with an dabcyl as an electrochemical tag to produce electrochemical signal from recongization occurrence. One special electrochemical marker was prepared by modifying PbS nanoparticle with -cyclodextrins (ab. PbS-CD), which employed as electrochemical signal provider and would conjunct with the codeine probe modified electrode through the host-guest recognition of to dabcyl. With codeine adding, aptamer folding allows the PbS-CD into soultion which caused a increased current signal. This sensor have the ability to detect $5.7 \mathrm{pM}$ codeine.
\end{abstract}

\section{Introduction}

Codeine(3-methylmorphine) is an opiate that is widely used to treat mild to moderate pain and cough suppression. It is the secondmost predominant alkaloid in opium with a mild sedative effect [1]. Despite its extensive medical applications, codeine is often abused for its euphoric and depressant effects as well as to prevent opiatewithdrawal [2]. It is very harmful to take codeine in large quantities

and now it has been attributed to be controlled medicine in mostcountries. It is very meaningful to detect codeine in forensic analysis or clinic diagnostics. There are many methods, such as UV spectrophotometric techniques [3], gas chromatography-mass spectrometry[4], capillary electrophoresis[5] and high-performanceliquid chromatography [6], have been applied in the determination ofcodeine. Although these above assay methods have accuracy and sensitive detection limit, it also has the obvious disadvantages of valuable apparatus, complicated manipulation and unapproachable in applying in field-tests. Therefore, it is highly desired to set up a sensitive method for detection of codeine.

In this article, the nolve electrochemical sensor was constructed for codeine detction. As illustrated in Fig. 1, two key components were employed for our electrochemical sensing codeine strategy. One component is the $\mathrm{PbS}$ nanoparticle surface-modified -cyclodextrins

\footnotetext{
* Corresponding author:fanhao11@aliyun.com
} 
(PbS-CD), which was used as both electrochemical signal provider and the host recognizer during the host-guest molecular recognition. The other one component is the 15-base codeine aptamer, which was terminal-labeled with dabcyl at its 5 end as -CD's typical guest and labeled thiol at its 3 end for pre-immobilization onto $\mathrm{Au}$ electrode via the $\mathrm{Au} \mathrm{S}$ bond. The aptasensor was completely fabricated after PbS-CD were interacted with aptamer-modified electrode through the host-guest recognition between dabcyl labeled at aptamer and -cyclodextrins-modified on CD. During codeine detection, conformational change of the aptamer happened and forced PbS-CD away from the electrode surface, thus the capture of target onto electrode was translated via the electrochemical current signal offered by released PbS-CD. Compare to previous methods, PbS-CD play the role of target recognition and the signal provider which make this present method display an simple-step detection and sensitivity. Therefore, this electrochemical aptasensor is expected to have wide applications in codeine monitoring.

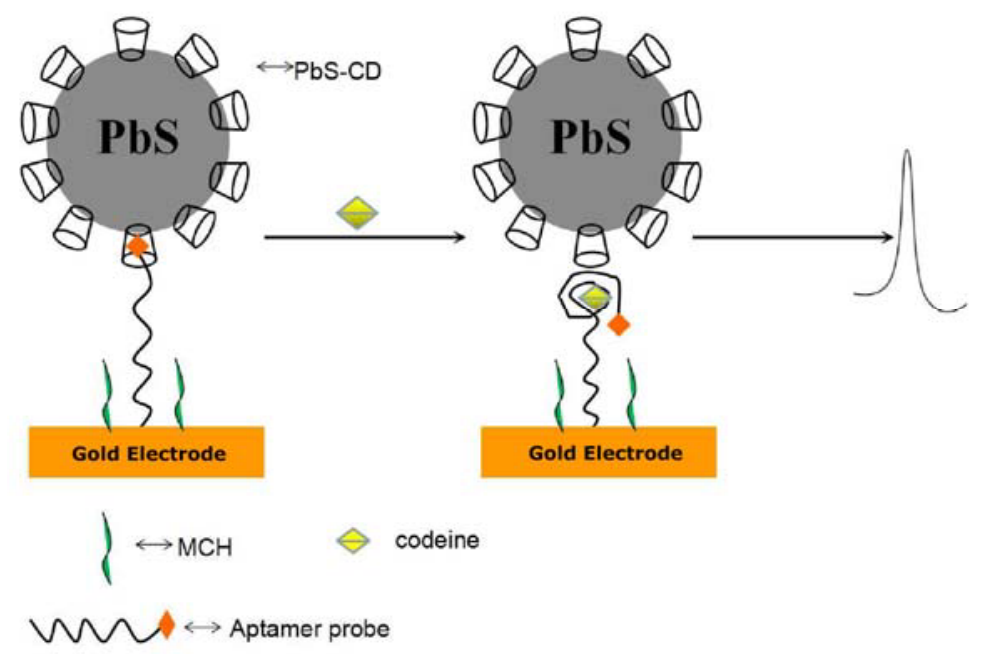

Fig.1 Schematic representation of the procedure to prepare electrochemical sensor for the determine of codeine.

\section{Experiment section}

\subsection{Materials and reagents}

The 1-ethyl-3-(3-dimethylaminopropyl) carbodiimide (EDC), 6-mercapto- 1-hexanol $(\mathrm{MCH})$ were purchased from Shen energy Biocolor Biological Science and Technology Inc. (Shanghai, China). The -cyclodextrins were purchased from Wacker Chemical Corporation. The nitric acid, sodium hydroxide, phosphate buffer $(0.1 \mathrm{M}, \mathrm{pH} 7.0)$, sodium acetate buffer $(0.1 \mathrm{M}, \mathrm{pH} 5.3)$ and other reagents were commercially available and of analytical reagent grade.

\subsection{Apparatus}

Differential pulse voltammetry (DPV) measurements were performed using a CHI 660 Electrochemical Analyzer (CHI Instrument Inc., USA). The JB-1 stirring machine (Branson, 
Shanghai, China) and a TDL-16B centrifuge (Anting Science Instrument Inc., Shanghai, China) were used. The three-electrode electrochemical detection system consisted of a $\mathrm{Au}$ working electrode with sensing area of $3.14 \mathrm{~mm} 2$, a $\mathrm{Ag} / \mathrm{AgCl}$ reference electrode (saturated $\mathrm{KCl}$ ) and a platinum wire counter electrode. The detection was carried out in a $5 \mathrm{ml}$ electrochemical cell containing a mercury-coated glassy carbon working electrode $(2 \mathrm{~mm}$ diameter), an $\mathrm{Ag} / \mathrm{AgCl}$ reference electrode, and a platinum wire counter electrode.

\subsection{Preparation of nano PbS}

$\mathrm{Pb}\left(\mathrm{NO}_{3}\right)_{2}$ and $\mathrm{Na}_{2} \mathrm{~S}$ solutions were filtered through a $22 \mathrm{~m}$ microporous membrane filter prior to use. $\mathrm{PbS}$ nanoparticles were prepared according to the literature [7] by using mercaptoacetic acid as the stabilizer. In brief, 9.22 1 mercaptoacetic acid was added to 50 $\mathrm{ml} 0.4 \mathrm{mM} \mathrm{Pb}\left(\mathrm{NO}_{3}\right)_{2}$ solution, and then the $\mathrm{pH}$ was adjusted to 7 with $0.5 \mathrm{M} \mathrm{NaOH}$. The solution was bubbled with nitrogen for $30 \mathrm{~min}$, followed by the slow addition of $1.34 \mathrm{mM}$ $\mathrm{Na}_{2} \mathrm{~S}$ to the mixture solution. The molar ratio of $\mathrm{Na}_{2} \mathrm{~S}$ to $\mathrm{Pb}\left(\mathrm{NO}_{3}\right)_{2}$ was kept at 2.5. The reaction was carried out for $24 \mathrm{~h}$ under nitro-gen protection and then gradually a brown colloid which is the PbS nanoparticles covered with a carboxyl group was obtained. As SEM images show, the diameter of PbS nanopatricles was about $5 \mathrm{~nm}$ (Fig.2).

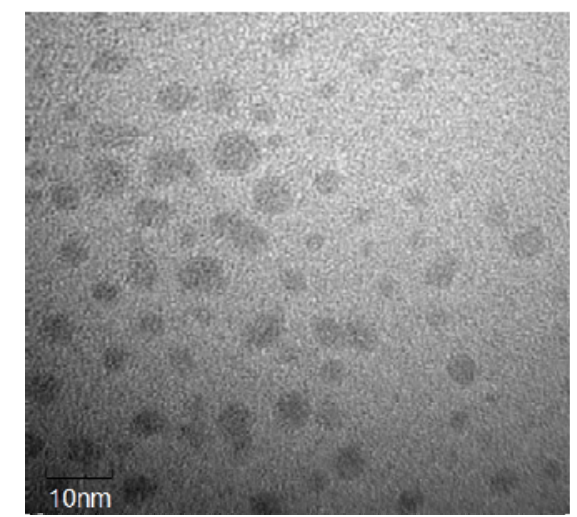

Fig. 2. SEM image of the synthesized $\mathrm{PbS}$ nanoparticles

\subsection{Preparation of Per-6-thio- $\beta$-cyclodextrin}

Per-6-thio- $\beta$-cyclodextrin (SH- $\beta$-CD) is synthesized according to the literature, but step slightly improved. The resulting precipitate was carefully filtered off and dried under vacuum to yield Per-6-thio- $\beta$-cyclodextrin $(0.85 \mathrm{~g}, 83 \%)$ as an off-white powder. $\mathrm{mp}$ 134-136 ${ }^{\circ} \mathrm{C} .{ }^{1} \mathrm{H}$ NMR (400 MHz, DMSO-d6) $\delta 5.92$ (d, $\left.J=6.0 \mathrm{~Hz}, 7 \mathrm{H}\right), 5.82$ (s, $\left.7 \mathrm{H}\right), 4.93$ (s, $7 \mathrm{H}), 3.68$ (t, $J=6 \mathrm{~Hz}, 7 \mathrm{H}), 3.61(\mathrm{t}, J=7.5 \mathrm{~Hz}, 7 \mathrm{H}), 3.19$ (br d, $J=15 \mathrm{~Hz}, 7 \mathrm{H}), 2.77-2.74$ (m, $7 \mathrm{H}), 2.13(\mathrm{t}, J=6.0 \mathrm{~Hz}, 7 \mathrm{H})$. MS (ESI) m/z [M Na]+: 1269.1920 (see fig.3). 


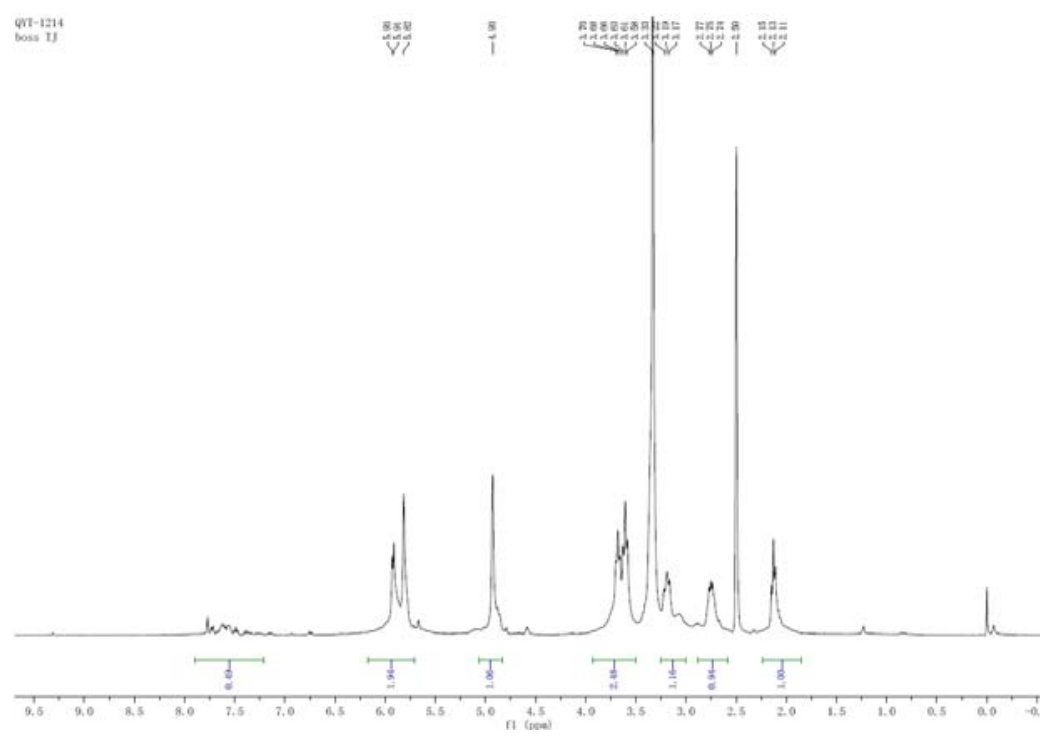

Fig.3 1H NMR of Per-6-thio- $\beta$-cyclodextrin

\subsection{Fabrication ofthe Aptasensor}

The sensor was fabricated on one gold electrode, and firstly, the gold electrode was successively polished with $0.3 \quad \mathrm{~L} \mathrm{~m}$ and $0.05 \quad{ }^{\mathrm{L}} \mathrm{m} \mathrm{Al} \mathrm{Al}_{2} \mathrm{O}_{3}$ suspension, washed ultrasonically with Milli-Q water, and electrochemically cleaned in $0.5 \mathrm{M} \mathrm{H}_{2} \mathrm{SO}_{4}$ by potential scanning between -0.35 and $1.5 \mathrm{~V}$ until a reproducible cyclic voltammogram was obtained. Then the fresh-prepared gold electrode was immersed in a 1.0 $\quad \mathrm{L}$ M aptamer solution for 12 $\mathrm{h}$, and then in a $1.0 \mathrm{mM} \mathrm{MCH}$ solution for $1 \mathrm{~h}$. After being rinsed with PBS and dried under nitrogen stream, such prepared aptamer probe DNA-modified gold electrode was immersed into $\mathrm{PbS}-\mathrm{CD}$ solution for $30 \mathrm{~min}$, during which the $\mathrm{PbS}-\mathrm{CD}$ molecules interacted with the dabcyl labeled on the probe owing to the host-to-guest combination. After rinsing the electrode with water and blowing it dry with nitrogen, we obtained the aptasensor for codeine detection.

\section{Results and Discussion}

\subsection{Principle of detection of codeine}

The assay procedure was initiated by incubating the aptasensor with codeine in phosphate buffer solution at $37^{\circ} \mathrm{C}$ for $40 \mathrm{~min}$. During which, the aptamer would prefer to bind with codeine due to

the strong combination between aptamer-to-protein and then the $\mathrm{PbS}-\mathrm{CD}$ which previously combined with aptamer were released away from the electrode surface (Fig. 1 ) into the buffer solution. These PbS-CD were dissolved by adding $20^{\mathrm{L}} \mathrm{L}$ of $1.0 \mathrm{M} \mathrm{HNO}_{3}$ into the buffer solution, and then $1.8 \mathrm{~mL}$ acetate buffer $(0.1 \mathrm{M}, \mathrm{pH} 5.3)$ was added into it. Electrochemical detection of the dissolved $\mathrm{Cd} 2+$ was performed in the above acetate buffer solution by applying $-1.0 \mathrm{~V}$ for $5 \mathrm{~min}$ at one mercury-film electrode to reduce $\mathrm{Pb}^{2+}$ into $\mathrm{Pb}$ film. After which, DPV was immediately performed from -0.90 to $-0.54 \mathrm{~V}$ (Incr E $0.004 \mathrm{~V}$, amplitude $0.05 \mathrm{~V}$, pulse width $0.05 \mathrm{~s}$, pulse period $0.2 \mathrm{~s}$ ), resulting in 
an electrochemical signal due to the oxidation of Cd film. The DPV peak height at the potential of $-0.56 \mathrm{~V}$ was used in all measurements, which was related to the released amount of the $\mathrm{PbS}$ nanoparticles from the electrode surface.

\subsection{Codeine determination}

In the experiments, the aptasensor was incubated with the different concentration of codeine, the DPV signal owing to the released PbS-CD was increased with the codeine concentration, which was logarithmically related to the target protein concentration from 7.3 $\times 10^{-12}$ to $7.3 \times 10^{-9} \mathrm{M}$. The equation for the resulting calibration plot was calculated as $\mathrm{y}=$ $0.12 \log \mathrm{x}-0.242$ ( $\mathrm{x}$ is the concentration of target codeine divided by $\mathrm{pM}, \mathrm{y}$ is the DPV peak current value) with correlation coefficient of 0.9832 and detection limit of $5.7 \times 10^{-12} \mathrm{M}$ (Fig 4).

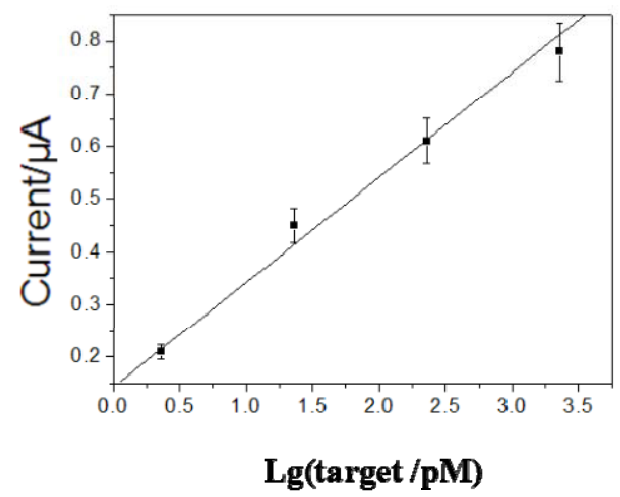

Figure 4, the Calibration curves for the determination of Codeine.

\section{Conclusions}

The present study has introduced a novel electrochemical aptamer biosensor based on $\mathrm{PbS}-\mathrm{PbS}$ as

signal label had been proposed to determine codeine and a very low detection limit of $27 \mathrm{pM}$ was achieved. Therefore, this electrochemical sensor is expected to have wide applications in medine monitoring.

\section{Acknowledgements}

This work was financially supported by the NSF of China (Grant No. 21265007) and JiangXi Science and Technology Committee (Grant No. 20122BAB215024, 20132BAB215032).

\section{References}

[1] M.A. Zayed, M.F. El-shahat, S.M. Abdullah, The use of IR, magnetism, reflectance, and mass spectra together with thermal analyses in structure investigation of codeine phosphate complexes of d-block elements, Spectrochim. Acta A 61 (2005),1955-1961. 
[2] D.G. Williams, A. Patel, R.F. Howard, Br. J.A Compartmental Analysis for Morphine and Its Metabolites in Young Children After a Single Oral Dose. Anaesth. 89 (2002) 839-843.

[3] T.T. Duong, D.H. Vu, Pharmaceutically active secondary metabolites of marine actinobacteria,Asian J. Res. Chem. 2 (2009) 143-151.

[4] L.A. Broussard, L.C. Presley, T. Pittman, R. Clouette, G.H. Wimbish, Quantitation of Opioids in Blood and Urine Using Gas Chromatography-Mass Spectrometry, Clin. Chem. 43 (1997) 1029-1034.

[5] A. Alnajjar, J.A. Butcher, B. McCord, Hair analysis for methamphetamine, ketamine, morphine and codeine by cation-sele,Electrophoresis 25 (2004) 1592-1598.

[6] Z.R. Chen, F. Bochner, A. Somogyi,A modified HPLC method for determination of morphine in biological fluids, J. Chromatogr. 491 (1989) 367-372.

[7] A.E. Radi, L.A. Sanchez, E. Baldrich and C.K. O'Sullivan,Ternary Surface Monolayers for Ultrasensitive (Zeptomole) Amperometric Detection of Nucleic Acid Hybridization without Signal Ampliation, Anal. Chem. Vol.77 (2005) 6320-6326. 